\title{
Ação coletiva para qualidade de vida: autonomia, transdisciplinaridade e intersetorialidade
}

\author{
Collective action for quality of life: autonomy, \\ transdisciplinarity and intersetoriality
}

Gert Ferreira Wimmer 1

Gustavo de Oliveira Figueiredo 2

\begin{abstract}
In this study the social work lived by it's authors have been taken as an object of analysis by the human sciences. We have related our living experiences in the Family Health Program and in the Program of Health Agents in order to show our way of constructing local intersectorial actions. This is a qualitative study having as main objective the discussion of the representations and values thru the social processes and thru the individual subjective processes. By doing the analysis of our interventions we will discuss the potentialities of the intersectorial actions in the work of promoting health.
\end{abstract}

Key words Collective action, Health quality, Autonomy, Transdisciplinarity, Intersectoriality
Resumo As práticas de trabalho intersetorial e transdisciplinar vivenciadas pelos pesquisadores no Programa de Saúde da Família e no Programa de Agentes Comunitários de Saúde (PSF/PACS) são tomadas como objeto de análise a partir do referencial teórico das ciências humanas. A reflexão crítica das intervenções discute como as ações coletivas intersetoriais e transdisciplinares, quando desenvolvidas com o objetivo de fortalecer a autonomia dos sujeitos e oxercício da contra-hegemonia politica, contribuem para a melhora da qualidade de vida da população.

Palavras-chave Ação coletiva, Qualidade de vida, Autonomia, Transdisciplinaridade, Intersetorialidade

\footnotetext{
1 Escola Nacional de Saúde Pública, Fiocruz.

Av. Leopoldo Bulhões 1.480, Manguinhos, 21041-210, Rio de Janeiro RJ. gertwimmer@yahoo.com.br 2 Escola de Governo em Saúde e ENSP, Fiocruz.
} 


\section{Apresentação}

Este estudo analisa a práxis dos pesquisadores com equipes de saúde nas comunidades da Vila do João e de Curicica no Rio de janeiro e à luz das idéias de transdisciplinaridade, qualidade de vida e ação intersetorial já que para Testa ${ }^{1}, 0$ profissional de saúde deve aliar a argumentação teórica à sua vivência prática e as suas vivências práticas ao embasamento teórico, numa relação recíproca e integrada. Nóvoa ${ }^{2}$ acredita que as reflexões dos profissionais sobre a sua prática não podem apenas se direcionar para teorias geradas em outros ambientes; são construídas a partir de sua realidade profissional. Em consonância com estes autores nos sentimos instigados a realizar uma análise crítica das nossas práxis num processo embasado no rompimento processual com um saber estático imposto e que rejeitamos ao longo de nossas vidas, principalmente na Faculdade de Odontologia onde, de acordo com Figueiredo ${ }^{3}$, os currículos de formação do profissional de saúde continuam impregnados pelo estudo de técnicas e patologias em detrimento das complexidades humanas e sociais.

Acreditamos que a complexa situação social de exclusão em que vive a maior parte da população não pode ser resolvida apenas com ações setoriais, mas a partir de micro e macroestratégias intersetoriais construídas em articulação por Estado e Sociedade Civil. A ineficiência das políticas públicas bem como das diferentes instâncias de gestão freqüentemente desviam recursos públicos e geram apatia. Entretanto, não podem impedir que as parcerias locais ocorram.

Antes de assumirmos uma abordagem teórico-metodológica, foi preciso reconhecer a perspectiva proposta por Thiollent 4 de que a visão de mundo dos pesquisadores e a de outros atores sociais sujeitos deste estudo estão implicadas em todo o processo de construção e que o estudo qualitativo tem o objetivo de captar representações e valores simultaneamente no "campo dos processos sociais" e no "campo dos processos subjetivos individuais". Optamos por reconhecer o caráter coletivo do trabalho prático que nos permitiu construir esses relatos de intervenção e, com o objetivo de valorizar o protagonismo das equipes das unidades de saúde em que trabalhamos, por utilizar conjugação verbal em primeira pessoa do plural.

O estudo se fundamenta na construção de ações coletivas embasadas na transdisciplina- ridade como um processo histórico de intervenção na realidade social complexa de comunidades onde se vive o processo de exclusão social.

Apresentaremos a seguir vivências com a equipe do Posto de Saúde da Vila do João, no Complexo da Maré, e com a equipe do Programa de Saúde da Família de Curicica, localizada no bairro de Jacarepaguá - ambas no município do Rio de Janeiro.

\section{Relato de intervenção no PACS da Vila do João}

O Complexo da Maré é constituído de 16 comunidades e habitado por 113.817 pessoas, segundo o Censo do Instituto Brasileiro de Geografia e Estatística (Brasil5). São 38.273 domicílios, formando o mais populoso conjunto de favelas do município do Rio de Janeiro e do Brasil 5 . A população da Maré representa, em sua maioria, a classe mais explorada pelo sistema capitalista: a da população de baixa renda. O Centro de Estudos e Ações Solidárias da Maré (CEASM), financiado pelo Banco Nacional de Desenvolvimento Social (BNDES), realizou, em 2000, um Censo no Complexo da Maré e verificou que, já na década de 1990, o número de analfabetos chegava a 20\%. Segundo dados do IBGE (Brasil5), já existia na região metropolitana do Rio de Janeiro, em agosto de 2003, cerca de 10 mil pessoas que gostariam e estavam disponíveis para trabalhar.

A taxa de analfabetos adultos da Maré é de 7,9\% e, ainda segundo o IBGE (Brasil5), o trabalho infantil atinge índices altos na Maré. Se for considerado que o analfabetismo é uma forma de despolitização da população, pode-se dizer que este fato é um reforço às práticas hegemônicas. Segundo Vázquez 6 a despolitização cria um imenso vazio nas consciências, o que só pode ser útil à classe dominante, uma vez que, a partir disso, as consciências são recheadas com atos, preconceitos, hábitos, lugares comuns e preocupações que colaboram para manter a ordem social. Entretanto há resistência, a Maré apresenta um grande desenvolvimento de ações populares, além de núcleos de atuação política e cultural que remontam aos princípios de sua história, quando as moradias no local eram palafitas.

Assim, como ficou patente na questão da educação, o acesso também é restrito em relação à saúde. Ao analisar a Constituição Brasi- 
leira e fazer uma comparação com a realidade de famílias da Maré, Wimmer ${ }^{7}$ afirma que falta saúde à grande maioria da população desta localidade.

Isto se justifica pelo fato de a fome ser uma realidade na Maré; de haver muitas moradias precárias em suas estruturas; valões a céu aberto estão presentes na comunidade sob o pseudônimo de canal; de ocorrência de violência urbana nesses espaços por conta de conflitos do tráfico com a polícia e de facções rivais do tráfico, o que torna muitas vezes o meio ambiente hostil; na Maré são muitos a enfrentar o desemprego; enormes filas atravessavam a madrugada para se conseguir uma vaga na escola pública; o lazer ocorre nos bailes locais ou nas ruas, nos espaços esportivos, bares, ONGs.

Não é possível, portanto, discutir políticas públicas em saúde, baseando-se apenas em aspectos biológicos, sem levar em conta os conhecimentos locais. Ampliando a discussão para Campos ${ }^{8}$, diz-se que só o reconhecimento de que todo saber estruturado é limitado por parte dos profissionais de saúde, já seria um caminho para uma clínica mais contextualizada e expandida.

Dando início aos trabalhos com a equipe de saúde bucal da UBS, fomos então realizar um grupo de puericultura, quando uma das mães presentes nos fez o seguinte questionamento: "A palestra é com o dentista? Eu queria ouvir o pediatra, aqui não tem nem cadeira de dentista!" Iniciou-se, então, a desvinculação de um futuro atendimento clínico da unidade, da atividade coletiva, explicando que as pessoas só deviam permanecer no recinto se tivessem vontade, mas, que seria um enorme prazer, para a equipe, poder conversar com elas. Prosseguiuse, dizendo que, apesar de sermos uma equipe de saúde bucal, não acreditávamos em falar só de boca como forma de promoção da saúde, inclusive bucal. E que, portanto, não se falaria só de dentes, mas sim, de assuntos que elas achassem interessantes. Este foi um dos grupos de puericultura mais construtivos de que já participei até hoje, e aquela que começou como opositora à realização foi quem, com seu senso critico, mais contribuiu, terminando por dizer que embora antes não estivesse entusiasmada a conversar com o dentista, saíra convencida de que ele era "gente boa".

Foi, portanto, necessário que se despisse da identidade autoritária legada ao dentista, para que a comunicação pudesse ocorrer. Para isso, realizou-se uma reflexão no sentido de esclare- cer que o grupo poderia trazer temas do cotidiano de suas vidas para serem debatidos.E, ainda, que a equipe não estaria ali para ditar regras de higiene bucal, mas para discutir a saúde da comunidade como conviesse ao coletivo, já que, por vezes, a possibilidade do atendimento clínico era vinculado à "palestra”. Cabe ressaltar, entretanto, que a identidade de profissionais de saúde bucal que nos é conferida em alguma hora despertou a curiosidade das pessoas pelos assuntos referentes à bucalidade, sem que tivéssemos imposto uma abordagem vertical do tema. É preciso que se respeite a curiosidade e os interesses da população quando se pretende construir ações realmente coletivas.

$\mathrm{Na}$ primeira reunião de equipe no posto, decidiu-se, a partir de uma demanda local, pela realização de um trabalho interdisciplinar, com um grupo de jovens de uma associação de moradores próxima ao posto, a respeito de sexualidade. Ao todo, participaram em torno de 500 adolescentes, divididos em grupos de 25 indivíduos, para os quais foram desenvolvidas oficinas de quatro encontros, abordando os seguintes temas: crescimento e desenvolvimento, métodos contraceptivos, gravidez, DST/ Aids, drogas lícitas e ilícitas. É importante ressaltar a idéia do conhecimento transdisciplinar trabalhado nessas oficinas, que respeitavam o direcionamento dado pela população, na busca por uma construção que desmembrasse o conhecimento técnico estruturado e o contextualizasse, corroborando para a definição de Vázquez 6 de que, só os homens são capazes de destruir o que eles mesmos criaram para abrir caminho a uma nova criação. As oficinas se desenvolviam, portanto, com dinâmicas de interação em que os conceitos eram produzidos coletivamente em lugar das entediantes palestras expositivas.

A culminância deste projeto se deu com um evento chamado "Espaço aberto à saúde", envolvendo vários projetos e instituições que atuam na Maré, como postos de saúde, Organizações não-governamentais (ONGs) e associações de moradores. Acredita-se que este projeto tenha sido um fator de integração para as entidades que trabalhavam com jovens naquela área, facilitando uma possível prática intersetorial futura, já que para a organização deste trabalho foram necessárias diversas reuniões. Neste evento, houve apresentação de circo; capoeira; cavaquinho; street dance; pesagem e medição da população; tenda de planejamento familiar e prevenção das DSTs; escovação supervisionada dos dentes, com distri- 
buição de kits de escovação e orientações à família com subseqüente atendimento dos casos de urgência odontológica pela equipe do posto da Vila do João em outro posto de saúde com o qual se estabeleceu uma parceria (um espaço contínuo para o atendimento clínico das urgências). E houve, ainda, tenda sobre hipertensão e diabetes, onde a população podia fazer o teste da curva glicêmica e aferir a pressão arterial; tenda de exposição de artesanato feito com material reciclado; tatuagem com rena; tenda de informações sobre os direitos da mulher. A interação das diversas instituições no sentido de uma formulação conjunta, pode-se dizer, foi um fator importante para a abrangência e magnitude do evento.

Aos poucos, a saúde bucal começou a permear os programas do posto de saúde. Certo dia se fez uma discussão com o grupo de hipertensos e diabéticos, a maior parte deles já na terceira idade, sobre os conceitos de saúde, a relação com o corpo e com a boca (edêntula ou não, incluam-se aí as próteses) e a necessidade de eles, como educadores dos seus filhos e netos, assumirem a responsabilidade pela saúde dos parentes mais jovens. No encontros subseqüentes com esse grupo, a equipe da Unidade organizou um café da manhã com a presença de um nutricionista na UBS. O objetivo foi criar uma oportunidade para se discutir as vantagens de uma alimentação saudável, em vez de chamar as pessoas para proibir o consumo de coisas que lhes dão prazer.

A equipe começaria agora a capacitação dos Agentes Comunitários de Saúde, em conjunto com a equipe de saúde bucal da Unidade Básica de Saúde Gustavo Capanema. O primeiro grupo a ser capacitado foi o de agentes do Posto de Saúde Gustavo Capanema, seguido pelo da Vila do João e da Nova Holanda. A capacitação constava de quatro momentos construídos coletivamente, quando se discutia: a concepção de saúde dos agentes; o conceito de saúde bucal deles e o nosso; a anatomia da cavidade bucal e abordagem que os agentes fariam na comunidade. Acredita-se, a partir desta experiência, que o trabalho com os agentes comunitários seja de suma importância para dar capilaridade a ações da equipe de saúde, permitindo uma maior abrangência das ações de mobilização da comunidade. A parceria com a equipe da UBS Gustavo Capanema nos permitiu atender às urgências da nossa unidade, já que eles nos cederam uma cadeira para o atendimento curativo.
O trabalho intersetorial em parceria com uma ONG permitiu-nos um trabalho conjunto com a assistente social do posto para jovens da região. Como proposta inicial, foram abordados os contrastes encontrados na comunidade; tudo aquilo que o grupo acreditava ser bom ou ruim na Maré. Na seqüência, discutiu-se sobre as barreiras físicas, sociais e psicológicas que lhes eram impostas pela sociedade e pelo Estado.

Chegou-se à conclusão de que a Maré é cercada por muros e grades, que "protegem" as principais vias de escoamento do Rio de Janeiro. Recentemente pudemos confirmar a sabedoria desses jovens, já que foi proposta pelo governo do Estado do Rio de Janeiro a construção de um muro em volta das vias expressas do Rio para "protegê-las” das favelas. Outra barreira discutida foi o preconceito que os jovens da Maré dizem sofrer, quando estão fora de suas comunidades. A repressão policial também foi considerada uma barreira pelos jovens, já que interfere no seu direito de ir e vir, assim como as barreiras impostas pelas diferentes facções do tráfico, que ocupam as comunidades da Maré. E o trabalho com os jovens teria fortes limitações, se os exemplos trazidos à discussão não viessem dos próprios jovens, já que, segundo Cordón ${ }^{9}$, reformar a estrutura sanitária deve levar em conta a criação de um modelo de atenção à saúde com co-responsabilidade, participante e democrático.

Decidiu-se, com os jovens, que era preciso que o grupo se apropriasse da cidade, já que muitos não conheciam as áreas de lazer gratuitas do Rio de Janeiro. O objetivo era incentiválos a ocupar o espaço urbano e discutir o direito de usufruto das qualidades da cidade. Fezse, então, um passeio à floresta da Tijuca e à cachoeira do Horto no Jardim Botânico, onde também se aproveitou para discutir a questão do lixo na Maré e a diferença dos climas entre um lugar arborizado e um local desprovido de árvores, como a Maré.

O trabalho com esses jovens teve a sua culminância realizada em evento, em um hotel na cidade de Nogueira, região serrana do Rio de Janeiro, graças a uma parceria realizada com o Sesc. Neste encontro, jovens de diferentes pólos e comunidades tiveram a oportunidade de demonstrar e discutir os seus respectivos trabalhos e de se entrosar através de práticas desportivas e do lazer. Vale ressaltar que muitos dos jovens talvez nunca tivessem se encontrado, já que moram em regiões diferentes muitas vezes proibidas de interação, por pertencerem aos 
domínios de diferentes facções do tráfico. Pensamos que a discussão da realidade local é de suma importância para a promoção da saúde coletiva. Sem ela, corremos o risco de sermos higienistas e fortalecedores de um sistema hegemônico (Gruppi10) que culpabiliza a população por problemas dos quais são vítimas. Há que se politizar até mesmo o ato de se escovar os dentes como uma opção pelo não consumo da tecnologia das amputações. Não se pode negar, aí, a necessidade de atendimento curativo, o qual é muito importante na atual condição de saúde da população.

\section{Relato de intervenção no PSF de Curicica}

A comunidade de Curicica localiza-se na região de Jacarepaguá, município do Rio de Janeiro, numa área com população de baixa renda, com ocupação desordenada dos espaços, não obedecendo às diretrizes de urbanização. O processo de favelização resultou da falta de uma política de habitação coerente com as necessidades da população, levando a um aumento de moradias precárias construídas em áreas sujeitas à erosão e a enchentes provocadas pelo transbordamento dos rios. O padrão de moradia popular reflete assim um dos efeitos da situação econômica precária em que vive a comunidade e do descaso do poder público. Não obstante o problema de moradia, a população enfrenta problemas mais graves como a fome crônica e aguda, falta de vagas em creches e escolas, enchentes, convívio diário com ratos e outros vetores de doenças, violência e abuso do poder policial, altos índices de desemprego, falta de perspectiva de futuro, abuso no uso de drogas lícitas e ilícitas com ênfase no álcool e na cocaína (o primeiro com maior prevalência entre adultos e o segundo com maior prevalência em adolescentes e adultos jovens).

O Programa de Saúde da Família de Curicica atende cerca de 3.980 famílias e 9.772 pessoas com apenas duas equipes de saúde da família composta por 1 supervisor (assistente social), 2 médicos, 2 enfermeiros, 1 dentista, 2 auxiliares de enfermagem, 1 técnico de saúde bucal e 1 auxiliar de saúde bucal. Como os profissionais possuem vínculo empregatício precário, freqüentemente a equipe entra em greve e suspende suas atividades por atrasos de até quatro meses nos salários.

Algumas informações estatísticas do Sistema de Informação em Atenção Básica podem auxiliar na compreensão do estado de miséria da comunidade: $99,1 \%$ das famílias não possuem sistema de descarte de esgoto, $93 \%$ das famílias convivem com lixo a céu aberto, 30\% das famílias sem acesso à água do sistema público de abastecimento e $68 \%$ das pessoas da comunidade não participam de nenhum grupo social na comunidade, enquanto somente cerca de $22 \%$ participam ao menos de grupos e associações religiosas.

Com o objetivo de construir junto com a população uma resposta que desse conta de discutir as diversas demandas coletivas da comunidade, a equipe de saúde da família propôs a articulação de uma ação coletiva intersetorial denominada 1o Encontro de Famílias.

O 1o Encontro de Famílias do PSF - Curicica aconteceu na Escola Municipal Silveira Sampaio e contou com a participação de 117 famílias da comunidade abrangida pelo programa e um número aproximado de 564 participantes dentre os 820 jovens e adultos inscritos para participar do encontro. As inscrições foram realizadas em dois dias no módulo do PSF - Curicica e tiveram de ser encerradas antes do prazo previsto devido à enorme procura. $\mathrm{Na}$ comunidade as Agentes Comunitárias de Saúde foram insistentemente abordadas por pessoas que exigiam uma vaga para a sua família no Encontro. Este fato já era previsto, uma vez que devido às restrições orçamentárias o evento havia sido planejado para apenas 800 pessoas, e isto equivale a cerca de $8 \%$ da população atingida pelo Programa. Portanto, apesar da alta eficiência qualitativa, numericamente tivemos um baixo impacto. O custo total de realização do evento, que preferimos denominar de investimento, não passou de quatro salários mínimos.

Com o objetivo de nos afastar do modelo assistencialista proposto pelos eventos organizados por políticos, fundações, redes de televisão, etc., optamos por trabalhar com a idéia de arte, lazer e educação política.

No dia do evento foram realizadas atividades de esporte, lazer e, com grande destaque, foram realizadas 17 oficinas de arte/educação diferentes dentre as quais cada pessoa poderia escolher por duas, a saber: teatro, música (com ênfase em hip hop e funk), reciclagem de lixo, artesanato, dança, capoeira, grafitagem, além de jogos e dinâmicas para a discussão de temas como drogas, sexualidade e organização popular da comunidade. Além das oficinas, foi realizada uma plenária popular com o objetivo de 
identificar as necessidades mais urgentes da comunidade e formar grupos de trabalho com o objetivo de desenvolver ações capazes de encontrar respostas para necessidades levantadas coletivamente.

Ainda como atividade do encontro, formou-se uma comissão para organizar a eleição de um Conselho Popular de Saúde, que será um grupo de pessoas eleito pela própria comunidade e trabalhará em parceria direta com o PSF - Curicica e com o Conselho Local de Saúde para organizar ações que possam melhorar a qualidade de vida da comunidade de Curicica, o que está de acordo com Jha11, quando afirma que a verdadeira democracia participativa ainda tem de surgir, já que democracia não deve ser reduzida a eventos eleitorais e ao direito a voto. Uma das principais condições para o exercício pleno da democracia é a capacidade de discutir abertamente e sem restrições os principais insumos nacionais e problemas que transcendem os limites nacionais, [...] no sentido de tomar-se decisões, que sejam uma reflexão dos desejos e sentimentos da população ${ }^{11}$.

Sem ações coletivas intersetoriais as práticas governamentais correm o risco de serem estruturalistas e orgânicas à hegemonia do Estado, acabando dessa forma a imaginação que o homem faz de si ("de si", neste caso, inclui todos os homens) por dominar o próprio homem (Marx ${ }^{12}$ ). Realizamos ainda neste dia um campeonato entre as famílias, de forma a proporcionar um momento de integração intra e extrafamiliar capaz de fortalecer vínculos e também criar um espaço de entretenimento. Os esportes e outras atividades de lazer como bingo e jogos de cartas serão estimulados, já que estas atividades podem reconhecidamente potencializar a formação de grupos.

\section{Objetivos e avaliação das ações coletivas desenvolvidas em Curicica}

1) Trabalhar a totalidade do núcleo familiar, estimulando a participação de todos os membros e proporcionando uma experiência comum à família

Este objetivo foi alcançado na medida em que presenciamos a freqüência de pessoas de diversas idades de uma mesma família, inclusive a figura paterna, sempre tão ausente da família porque tem de trabalhar e ser explorado nas atividades do dia-a-dia. Ao oferecer diversas atividades simultaneamente, tivemos a pre- ocupação de proporcionar prazer para os diversos segmentos etários que formam a mesma família, o que viabilizou a possibilidade da escolha entre ficar em atividades diferentes ou participar de uma mesma atividade. Seja qual tenha sido a opção, a família teve uma experiência comum, um momento de aprendizado e lazer que despertou a curiosidade e o interesse de seus integrantes como um todo e, certamente, se tornou numa experiência de vida forte naquele contexto, criando referências afetivas, laborativas ou mesmo políticas.

2) Promover a integração das diferentes famílias por meio de ações coletivas - educativas e culturais -, de forma a possibilitar o questionamento da realidade concreta em que se vive em Curicica

A integração entre as famílias ocorreu durante as apresentações artísticas da abertura do evento, durante as oficinas, o almoço, as brincadeiras, o lanche e o show de encerramento. Foi possível observar desde crianças fazendo passos de balé, até um casal de idosos aprendendo a fazer pátina em madeira. Não podemos deixar de citar os diversos casais adolescentes, grávidos ou não, das crianças que pintavam enquanto os pais bordavam. Não podemos esquecer da mãe que amamentava ao seio sua criança que conhecemos nas consultas de puericultura ou até mesmo antes pela ultra-sonografia do pré-natal. Ainda mais injusto seria deixar de sublinhar a presença vigorosa dos homens. Homens que o Programa de saúde da Família raramente atende, porque ele está trabalhando. Eles também estavam lá, discutindo a organização comunitária, aprendendo a fazer caixas de presente, pintando ou jogando capoeira.

3) Criar um espaço que proporcione um momento de lazer onde as famílias possam conhecer pessoas, fazer amizades e fortalecer vínculos, uma necessidade sentida pela comunidade e de fundamental relevância para estimular a participação popular no PSF

Nestes momentos de lazer que compreenderam bingo, gincana de atividades, pelada de futebol ou ginga de capoeira, as diversas famílias puderam se conhecer (ou re-conhecer) e afirmar sua identidade de vizinhos e de moradores das comunidades expropriadas de Curicica. Com estes encontros se formaram novos 
vínculos afetivos, novos contatos, novas possibilidades de relação entre aquelas pessoas. Esta integração facilitou também a percepção de que os problemas são comuns a todos e não simplesmente problemas individuais. Foi possível perceber, portanto, que o desemprego e o saneamento básico (água, lixo e esgoto) são problemas maiores que as capacidades individuais de reivindicação e que se faz necessária uma união em torno de objetivos comuns para que se possa atingir uma melhoria na qualidade de vida local.

4) Discutir com as famílias presentes os fatores que interferem em sua qualidade de vida e as formas possíveis de se organizar para lutar por seus direitos e reivindicar, de forma ativa, dos órgãos do governo um conjunto de ações capaz de resolver as principais necessidades levantadas

Devido a um atraso na agenda, não foi possível realizar uma discussão com a totalidade das pessoas presentes no evento. Optou-se, então, por estimular a reflexão sobre os problemas da comunidade somente entre as pessoas que claramente demonstrassem interesse em discutir os problemas de saúde da região. Sendo assim, unimos o grupo que na parte da manhã havia ficado na oficina de participação popular ao grupo que na parte da tarde se interessou em conversar um pouco sobre qualidade de vida. Agendou-se uma reunião deste grupo naquela mesma semana, participando do encontro mais de 15 pessoas da comunidade, que discutiram um pouco mais sobre a política de Curicica, as estruturas de poder já existentes e a necessidade de criar vias alternativas de associação dos moradores em torno dos problemas comuns. Este grupo está sendo articulado para participar do 1o Encontro Popular de Saúde, que será realizado como uma atividade preparativa para a Conferência Distrital de Saúde. Acreditamos que, com a continuidade do trabalho, será possível organizar um grupo de pessoas, líderes da comunidade, para participar da conferência e, assim, institucionalizar as reivindicações dos moradores de Curicica e pressionar os órgãos do governo para adoção de um conjunto de ações que seja capaz de resolver as principais necessidades levantadas.

5) Organizar a comunidade para que seja capaz de formar parcerias com instituições públicas e privadas, no sentido de promo- ver um maior desenvolvimento socioeconômico na região

Ainda se constitui um grande desafio para a equipe organizar estas lideranças comunitárias identificadas durante o trabalho para que, efetivamente, se constituam um grupo de pressão para as estruturas locais de poder. Mais desafiador ainda será fazer a comunidade acreditar que o imobilismo que lhe é imposto pode ser rompido por meio de um esforço conjunto. Sem o apoio da comunidade, este evento não teria ocorrido pois dela mesma foi a financiadora de metade do evento. A Gincana de Adolescentes, outra ação coletiva realizada pelo PSF - Curicica, que reuniu cerca de 400 adolescentes e foi acompanhada e avaliada pelo Centro de Informação Científica e Tecnológica do Departamento de Comunicação e Saúde da Fundação Oswaldo Cruz (Araújo e Cardoso13), foi mais uma constatação de que a organização intersetorial e a união transdisciplinar em torno de um esforço comum são capazes de fazer uma pequena revolução. A articulação com o setor privado ainda é difícil de se atingir em nível local e comunitário já que somente prestam auxílio se têm um eficiente programa de "responsabilidade social" que financia ações aprovadas pelas diretorias de marketing com dinheiro do governo camuflado pelos descontos no Imposto de Renda ou algum interesse específico no território da comunidade.

\section{Reflexão a partir da práxis}

\section{Ação coletiva, intersetorialidade, transdisciplinaridade e autonomia}

A complexidade do setor saúde não permite uma abordagem dos problemas que se realize de forma fragmentada por estruturas setorializadas. Para enfrentar de forma eficiente os problemas de saúde em que vive a população, somente ações coletivas, intersetoriais, transdisciplinares e que proporcionem o desenvolvimento de autonomia nos sujeitos podem apresentar resultados satisfatórios (Junqueira et al. 14 , Junqueira e Inojosa15).

O caminho para a estruturação de ações coletivas mais complexas, que dêem conta da realidade e de suas diversas nuances, é a articulação intersetorial e transdisciplinar. A intersetorialidade é uma prática integradora de ações de diferentes setores que se complementam e 
interagem, para uma abordagem mais complexa dos problemas.

Para a Rede Unida16, a construção e a viabilidade política de um projeto intersetorial passa por um novo olhar e um novo agir sobre a realidade, sob a lógica de problemas prioritários, definidos democraticamente, cuja redução ou controle necessita de conhecimentos, habilidades e compromissos de vários setores, cujos sujeitos precisam encontrar novas formas de relação com os outros. Um aspecto importante da intersetorialidade é, como afirma Bourguignon 17 , a possibilidade de enfrentamento de problemas multidimensionais como a exclusão social, que exige uma abordagem marcada pela complexidade e pelo pensamento transdisciplinar.

A transdisciplinaridade, segundo Piaget, não se limita às interações e à reciprocidade, mas inclui essas interações em um "sistema total" sem limites entre as disciplinas. Esta perspectiva está certamente mais próxima de atingir as necessidades da comunidade de forma integral. Quando se fala de transdisciplinaridade não está se falando de uma "geléia geral" de Campos ${ }^{8}$, mas sim, de uma abordagem, que seja "[...] complementar à aproximação disciplinar”.

Segundo a Carta da Transdisciplinaridade 18 , pensar transdisciplinarmente deve promover não só um diálogo das ciências exatas com as humanas, como também levar em conta fatores como as artes, mitos e religiões. $\mathrm{O}$ que está de acordo com a concepção de autonomia proposta por Freire ${ }^{19}$ quando afirma que educar é proporcionar autonomia de escolhas, uma cultura de vida, associando à idéia de autonomia a idéia de liberdade e de força pessoal e coletiva para intervenção na realidade e escolha dos próprios caminhos. Para Carvalho ${ }^{20}$, os estudos em saúde pública proporcionam o desenvolvimento de autonomia quando orientam os profissionais no sentido da realização de uma "reforma organizacional", que permita a inclusão de novos sujeitos na construção de projetos para a saúde.

Acreditamos que pelas ações coletivas é possível intervir na realidade local por meio da prática da intersetorialidade, da transdisciplinaridade e da educação para autonomia. Assim estamos mais próximos de pensar as necessidades da comunidade de forma mais ampla e de agir nos problemas de forma menos pontual e considerando toda sua complexidade. As construções relatadas nas duas intervenções, tanto de Curicica quanto da Vila do João, seriam im- possíveis não fosse: 1) a valorização e incorporação da sabedoria local; 2) o esforço transdisciplinar da equipe das unidades básicas de saúde e 3 ) as parcerias com outros setores transversais ao setor saúde.

\section{Construir é enfrentar problemas e propor}

Neste estudo analisamos ações coletivas desenvolvidas pelas equipes do Programa de Saúde da Família de Curicica e do Posto de Saúde da Vila do João. Optamos por elaborar um relato que valorizasse a idéia de que construir é enfrentar problemas e propor soluções, levando em consideração a possibilidade de contra-hegemonia inerente a qualquer espaço político, estimulando a crítica social e a compreensão de que a realidade de vida que se vivencia na pobreza não é natural, mas reflexo da exploração social histórica gerada pelo lucro.

A partir de nossa experiência, podemos afirmar que nas lutas hegemônicas e contrahegemônicas, a produção e a regulamentação do desejo são tão importantes quanto a construção do significado e que a idéia e a experiência do prazer devem ser construídas politicamente, para que se possa analisar como o corpo se torna sujeito do prazer. Neste caso, de acordo com Botazzo 21 , o próprio prazer se torna o consentimento da vida no corpo e proporciona uma importante condição corpórea da vida, e talvez um importante instrumento/momento revolucionário.

O profissional de saúde, o sanitarista, o educador, etc. podem - e devem - apoiar a comunidade para que ela mesmo vença as suas dificuldades, e estas não devem ser ditadas por um único setor, mas construídas numa discussão intersetorial que fortaleça um processo de tomada de consciência e de enfrentamento dos problemas vividos na realidade cotidiana pela comunidade. Para tanto, faz-se necessário que, além da capacidade científica, do domínio técnico e da ação política, tenhamos ainda compromisso com o desenvolvimento de autonomia da comunidade fundamentado em certas atitudes como amor, escuta, afetividade, respeito, tolerância, humildade, alegria, gosto pela vida, abertura ao novo, disponibilidade à mudança, esperança, abertura à justiça. É necessário, então, auxiliar na descolonização vivida pelas pessoas da comunidade em seu corpo, trabalhando com arte, cultura e subjetividade, 
ou seja, seus sentimentos, emoções, e verdadeiros desejos no intuito de fortalecer os processos de tomada de consciência e conquista da autonomia.

Ressaltamos a necessidade e a importância de uma integração plena com a comunidade no levantamento crítico das suas necessidades e problemas garantindo uma interpretação dialética e transdisciplinar da realidade.

As ações coletivas podem ser desenvolvidas como estratégias eficientes para a melhoria da qualidade de vida da população, quando se fundamentam na intersetorialidade, na transdisciplinaridade e no desenvolvimento de autonomia dos sujeitos, já que permitem não somente a discussão dos problemas que afetam a comunidade como também possibilitam a construção coletivas de estratégias de intervenção.

A análise das intervenções nos permite enumerar alguns resultados relevantes que legitimam as ações coletivas como estratégias indispensáveis para a melhora da qualidade de vida visto que possibilitam: 1) uma abordagem transdisciplinar dos saberes baseada no confrontamento, na reconstrução e na articulação das diferentes especialidades dos atores envolvidos, das realidades e organizações dos setores cujas ações tenham impacto nas condições de vida da população; 2) práticas intersetoriais, que possibilitam uma maior integralidade de atuação de diferentes setores que se complementam e interagem para uma abordagem mais complexa dos problemas da saúde; 3) autonomia dos sujeitos e mobilização popular, com o empoderamento do direito à vida com qualidade e a partir de uma participação mais ativa no diagnóstico de problemas e na geração de iniciativas - inclusive políticas para enfrentamento e resolução.

Como conclusão da reflexão realizada a partir de nossa práxis afirmamos que as ações coletivas intersetoriais e transdisciplinares, quando desenvolvidas com o objetivo de fortalecer a autonomia dos sujeitos e o exercício da contra-hegemonia política, contribuem para a melhora da qualidade de vida da sociedade.

\section{Colaboradores}

GF Wimmer e GO Figueiredo trabalharam no relato de intervenção do PACS da Vila do João e do PSF de Curici$\mathrm{ca}$, respectivamente, e trabalharam igualmente nas demais partes do artigo.

\section{Agradecimentos}

Agradecemos especialmente as equipes do Posto de Saúde da Vila do João e do Programa de Saúde da Família de Curicica pela oportunidade do trabalho coletivo. Não haveria ainda como deixar de agradecer ao sr. secretário de Saúde dr. Ronaldo César Coelho e ao Ilmo sr. prefeito César Maia que pela ingerência com que administram a Secretaria de Saúde do Município do Rio de Janeiro nos possibilitaram aprender a despeito do caos, da falta de recursos e das péssimas condições de trabalho. Foi com a comunidade que passamos a acreditar ser possível trabalhar e viver mesmo com a indignação frente ao poder publico. 


\section{Referências}

1. Testa M. Pensar em saúde. Porto Alegre: Artes Médicas, 1992.

2. Nóvoa A, Goodson IF, Gonçalves JAM, Moita MC, Fontana MM, Holly ML et al. Vidas de professores. Porto: Porto Editora; 1995.

3. Figueiredo GO. Do fetichismo odontológico à utopia da saúde bucal [dissertação]. Rio de Janeiro: Núcleo de Tecnologia para a Saúde, Universidade Federal do Rio de Janeiro, Rio de Janeiro; 2002.

4. Thiollent M. Crítica metodológica, investigação social e enquete operária. 5a ed. Rio de Janeiro: Polis; 1987.

5. Brasil. Ministério do Planejamento, Orçamento e Gestão. Instituto Brasileiro de Geografia e Estatística. Estatísticas populacionais, sociais, políticas e culturais. 2003. [acessado 8 out 2003]. Disponível em: http:// www.ibge.gov.br

6. Vázquez AS. Filosofia da práxis. Rio de Janeiro: Paz Terra, 1977.

7. Wimmer GF. O processo de trabalho da Rede Maré Jovem como Estratégia para a Promoção de Saúde [monografia de especialização]. Orientador: Gustavo de Oliveira Figueiredo. Brasília: UnB, 2004

8. Campos GW S. Saúde paidéia. São Paulo: Hucitec; 2003

9. Cordón J. A construção de uma agenda para a saúde bucal coletiva. Cad Saúde Pública 1997; 13(3).

10. Gruppi L. Conceito de hegemonia em Gramsci. Rio de Janeiro: Graal, 1978. [Biblioteca Estudos Humanos. Série Teoria Política 1]

11. Jha SS. Empowering people for health. Promotion \& Education, vol. 5, 1998.

12. Marx K, Engels F. A ideologia alemã e outros escritos. Rio de Janeiro: Zahar; 1965.

13. Araújo IS, Cardoso JM. Promoção da Saúde e Prevenção do HIV/Aids no Município do Rio de Janeiro Uma metodologia de avaliação para políticas públicas e estratégias de comunicação. Relatório de Pesquisa: No.CFA: 710/01, Rio de Janeiro, julho - 2003.

14. Junqueira LAP, Inojosa RM, Komatsu S. Descentralização e intersetorialidade na gestão pública municipal no Brasil: a experiência de fortaleza. In: XI Concurso de Ensayos del CLAD "El Tránsito de la Cultura Burocrática al Modelo de la Gerencia Pública: Perspectivas, Posibilidades y Limitaciones”. 1997 [acessado 5 dez 2003]. Disponível em: http://unpan1.un.org/in tradoc/groups/public/documents/clad/unpan 003743.pdf

15. Junqueira LAP, Inojosa RM. Desenvolvimento social e intersetorialidade na gestão pública municipal. In: Conferência Nacional de Saúde Online: uma proposta em construção. 1997. [acessado 5 dez 2003]. Disponível em: http://www.datasus.gov.br/cns/inovador/ FORTALEZA.htm.

16. Rede Unida. Intersetorialidade na Rede UNIDA. Saúde em Debate 2000; 24(55).

17. Bourguignon JA. Concepção de rede intersetorial. 2001. [acessado 5 dez 2003]. Disponível em: http://www. uepg.br/nupes/intersetor.htm.

18. Carta de Transdisciplinaridade. Primeiro Congresso Mundial da Transdisciplinaridade. Convento de Arrábida, Portugal, 2-6 novembro. 1994. [acessado 10 nov 2003] Disponível em: http://www.cetrans.futu ro.usp.br/textos/documentos/c_carta_transp.htm

19. Freire P. Pedagogia da autonomia: saberes necessários à prática educativa. São Paulo: Paz e Terra, 1996.

20. Carvalho AI. A educação à distância e a nova saúde pública. 2000. [acessado 7 set 2005]. Disponível em: www.ead.fiocruz.br/profae/biblioteca/saude_publi ca.pdf .

21. Botazzo C. Saúde bucal: transitando entre a teoria e a prática. In: Pereira AC. Odontologia em saúde coletiva: planejando ações e promovendo saúde. São Paulo: Artmed, 2003. p. 17-27.

Artigo apresentado em 25/06/2005

Aprovado em 17/08/2005

Versão final apresentada em 12/09/05 